\title{
Development of a unified treatment system for public use of discharged water from a Korean apartment complex for urban infrastructure regeneration
}

\author{
C. Choi ${ }^{1}$, K. Park ${ }^{1}$, W. Park ${ }^{2}$ \& H. Park ${ }^{2}$ \\ ${ }^{1}$ KIUSS, KAIST, Korea \\ ${ }^{2}$ Department of Civil \& Environmental Engineering, KAIST, Korea
}

\begin{abstract}
The purpose of this study was to enhance major economies and compatibilities of the system, comparing the differences of footprints between outdated and updated systems. In addition, the research provided ways to verify the effluent quality during the pilot-plant scale operation of a unified treatment system (MBR and Coagulation-LPCF) and estimate the great economical efficiency in the proper construction and operation. As the results of a real pilot plant, the effluents contained low concentrations for BOD, at $3.3 \mathrm{mg} / \mathrm{L}$, followed by 7.2 $\mathrm{mg} / \mathrm{L}$ COD, $8.47 \mathrm{mg} / \mathrm{L} \mathrm{T-N}$ and $0.1 \mathrm{mg} / \mathrm{L}$ T-P. The MBR-LPCF system was reported to occupy a plot of $384 \mathrm{~m}^{2}$, which had a two times lower square compared to the outdated system (RBC; Rotating Biological Contactor). What is more, by comparing prices, the reclaimed water system experienced a decrease of nearly $76 \%$ in a unit cost of tap water involving facility renovation and operation. Consequently, if the MBR-LPCF system starts to be operational in an apartment complex, it can significantly not only enhance the amenity of the housing complex, but also increase green efficiency to decrease the use of water resources.
\end{abstract}

Keywords: urban infrastructure regeneration, reclaimed water and water recycling. 


\section{Introduction}

In order to point towards green growth, technological innovations have been introduced and defined as an ascent work in terms of increasing recycling, renewable energy and sustainable thriving development [1-3]. The targets of these technologies can be matched to the needs of the urban infrastructure systems concerned. From a practical point of view, this ensures that the design can be adapted successfully to each unit of a housing complex. Hence, it is expected that the new design using reclaimed water will bring considerable advantage in water spaces and facilities, which provide an amenity for local residents in a housing complex.

The results of the study have shown that the unified treatment system will derive potential benefit from discharging water, purifying rainwater, ground water and wastewater to the apartment complex. The new system is a winning combination process of MBR (Membrane bioreactor) and LPCF (Lifted pore control fibre) filter and both of them use filtration after biological treatment and coagulation [4]. It results a massive increase in the recycling rate of producing reclaimed water for public use and improvement in effluent's water quality in a complex. In this manner, effluent quality, footprint and economical efficiency should be investigated ahead of the application as the new system is adopted.

There are the regenerable facilities of 109,508 sites $\left(>10 \mathrm{~m}^{3} /\right.$ day), including 45,938 plants not in use at a building and APT complex because of the operation of municipal wastewater treatment facility [5]. These facilities can be fully used for both water recycling and unified treatment system for rainwater, groundwater and wastewater by a simple renewal in each and every complex. It leads to an increase of recycling rate producing reclaimed water for public use. In this way, effluent quality, footprint and economical efficiency should be investigated ahead of the field application of the new system. Therefore, this study helps to enhance the economical and compactable system, compare the differences of footprints between outdated and updated systems, verify the effluent quality through the pilot-plant scale operation of new system and estimate the great economical efficiency in constructing and operating.

\section{System configuration}

The combination process of MBR and LPCF can also obtained with the new system in which they both use filtration after biological treatment and coagulation process. In the course of this operation, an in-line device is installed before the LPCF process to address the coagulation process. While MBR focuses particularly on detection and removal of the organic matter, SS (suspended solid), nitrogen and bacteria by assimilation and separation, LPCF removes the fine SS, phosphate and bacteria by coagulation and filtration. Hence, The MBRLPCF system is to be expected to meets the standards of quality required for the reclaimed water and also achieves both compactness and economy of which set up the system. 

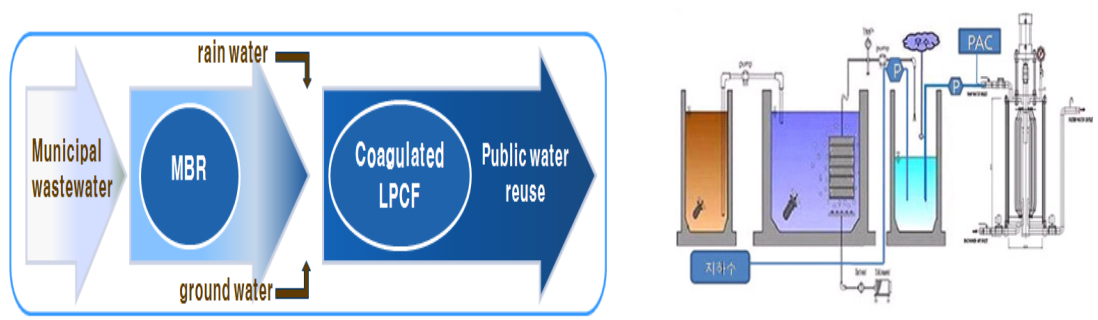

Figure 1: Introduction of unified treatment system for reclaimed water production.

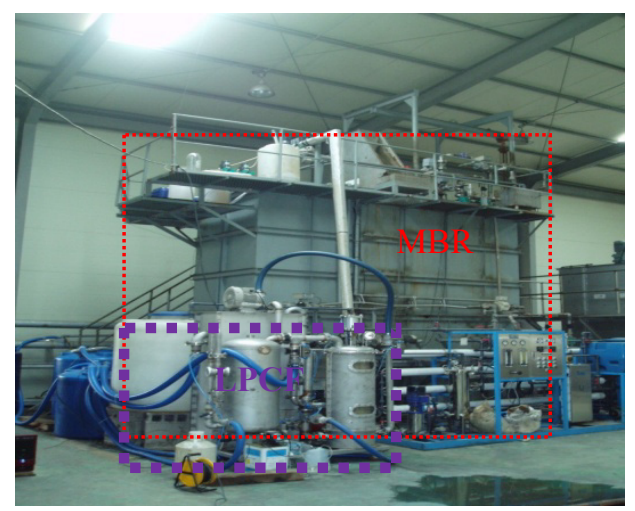

Figure 2: $\quad$ Field plant of a unified treatment system.

Table 1: $\quad$ Permeate concentration of a unified treatment system.

\begin{tabular}{|c|c|c|c|c|c|c|}
\hline & \multirow{2}{*}{ standard } & \multirow{2}{*}{ raw } & \multicolumn{2}{|c|}{ MBR permeate } & \multicolumn{2}{|c|}{ Coagulation-LPCF } \\
\hline & & & Conc. & Eff. (\%) & Conc. & Eff. $(\%)$ \\
\hline $\mathrm{pH}$ & $5.8 \sim 8.5$ & 7.03 & 6.64 & - & 6.14 & - \\
\hline SS(mg/L) & 6 & 120 & 0 & 100 & 0 & 100 \\
\hline $\operatorname{coD}(\mathrm{mg} / \mathrm{L})$ & 40 & 136.4 & 14.2 & 89.6 & 7.2 & 94.7 \\
\hline $\mathrm{BOD}(\mathrm{mg} / \mathrm{L})$ & 3 & 128.3 & 3.5 & 97.3 & 3.3 & 97.4 \\
\hline Chromaticity & 5 & - & 41.9 & - & 25.1 & - \\
\hline$C_{\ell-(m g / L)}$ & 250 & 101.4 & 109.9 & - & 124.1 & - \\
\hline$T-N(m g / L)$ & 10 & 24.49 & 8.6 & 64.9 & 8.47 & 65.4 \\
\hline$T-P(m g / L)$ & 1 & 3.8 & 1 & 73.7 & 0.1 & 97.4 \\
\hline ABS (mg/L) & 1 & 1.012 & 0.027 & 97.3 & 0.05 & 95.1 \\
\hline $\begin{array}{l}\text { Coliform } \\
\text { (ea/100mL) }\end{array}$ & ND & ND & ND & - & ND & - \\
\hline
\end{tabular}




\section{Field application}

\subsection{Pilot test}

The pilot plant of this system was conducted at O WWTP (waste water treatment plant). The experimental results obtained in the real pilot plant indicates very low concentrations of BOD, COD, Cl-, T-N, and T-P in the treated effluent at 3.3 $\mathrm{mg} / \mathrm{L}, 7.2 \mathrm{mg} / \mathrm{L}, 124.1 \mathrm{mg} / \mathrm{L}$, and $8.47 \mathrm{mg} / \mathrm{L}, 0.1 \mathrm{mg} / \mathrm{L}$, respectively. In particular, both SS and Coliform outcome showed diminished concentrations in the samples at $0 \mathrm{mg} / \mathrm{L}$. It can be seen that every concentrations of effluent meet the water quality standards for the reclaimed water. However, chromaticity is not appropriate for the target, because this system is constituted with two step filtration and filtration process which can merely remove the chromaticity of influent. Therefore, the system is pressingly in need of an additional process to solve this problem. The real photo and the concentrations of field plant are described in detail below.

\subsection{Space estimation}

To investigate the field applicability, it is necessary to examine carefully the possibilities that the system could reside in the real sewage treatment facility of an apartment complex. The process is RBC (Rotating Biological Contactor) operated with two tanks. The MBR-LPCF system is expected to be occupied by comparing $384 \mathrm{~m}^{2}$ of the new system with $702 \mathrm{~m}^{2}$ of outdated system and all this proves that recent development is more compactable than that system remains unrepaired. It proves that new system is more compactable than old one.

\section{Economic analysis and benefit}

According to the results from the economic analysis of the reclaimed water usage between MBR-LPCF process and tap water, a unit cost of reclaimed water

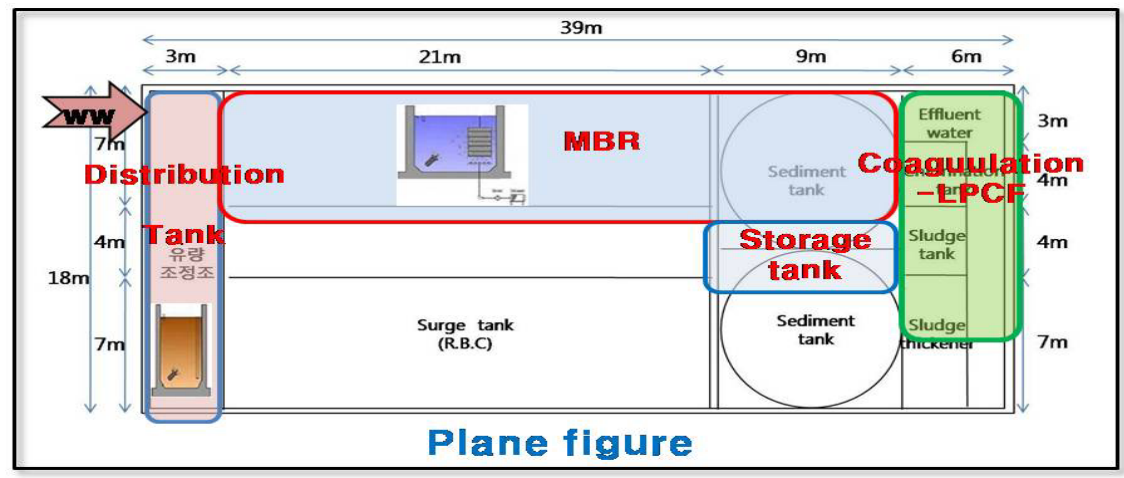

Figure 3: $\quad$ Plane figure of a unified treatment system compared to $\mathrm{RBC}$ in the field. 

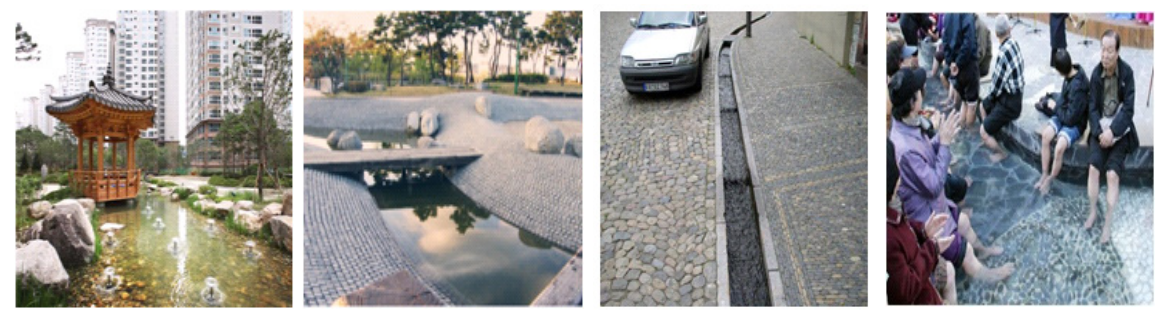

Figure 4: Adaptable water facilities for an amenity enhanced apartment complex.

including facility renovation and operation is $0.13 \mathrm{USD} / \mathrm{m}^{3}$ which could be compared with $0.55 \mathrm{USD} / \mathrm{m}^{3}$ of tap water providing a cost for the tap water rate, water pumping, tax and maintenance of municipal sewer treatment facility. This means that 50,545USD/yr could be saved and MBR-LPCF application for reclaimed water is remarkably successful in an apartment complex.

By the use of reclaimed water, water spaces can be recovered to make use of waterfalls, aquatic-ecological parks, foot spa, artificial waterway, etc. Eventually, it improves an urban green efficiency and provides an amenity for local residents.

\section{Conclusion}

Through the pilot test, it represents that the unified treatment system can be adopted to produce the reclaimed water. From the estimation of present occupied space for $\mathrm{H}$ apartment complex, the new system clearly shows that it is more compactable than the ordinary one before. As the result of economical analysis, a unit cost of reclaimed water including facility renovation and operation is $0.13 \mathrm{USD} / \mathrm{m}^{3}$ which is better to compare $0.55 \mathrm{USD} / \mathrm{m}^{3}$ of tap water.

It goes without saying that the results helped the system reach a consensus on the plan for future municipal wastewater infrastructure by means of increasing the recycling rate of wastewater, making various water-friendly spaces for urban regeneration. Therefore, it is possible to provide an amenity for local residents as well as increase green efficiency towards a decrease in the use of water resource.

\section{Acknowledgement}

This research was supported by a grant (07-UR-BO4) from the High-tech Urban Development Program funded by the Korea Ministry of Land, Transport and Maritime Affairs.

\section{References}

[1] Ha S., Housing regeneration and building sustainable low-income communities in Korea, Habitat International, Vol. 31, 116-129, 2007. 
[2] Zhang J., Cao X., and Meng X., Sustainable urban sewerage system and its application in China, Resources, Conservation and Recycling, Vol. 51, 284293, 2007.

[3] Patsy H., The institutional challenge for sustainable urban regeneration, Cities, Vol. 12, No. 4, 221-230, 1995.

[4] Park W., Choi C., and Park H., Development of water reuse system for urban public use by membrane bioreactor and coagulation-lifted pore control fiber filter, Conference of Korean Society on Water Quality, 149$150,2009$.

[5] Korean Ministry of Environment, Statistics of wastewater, 2007. 